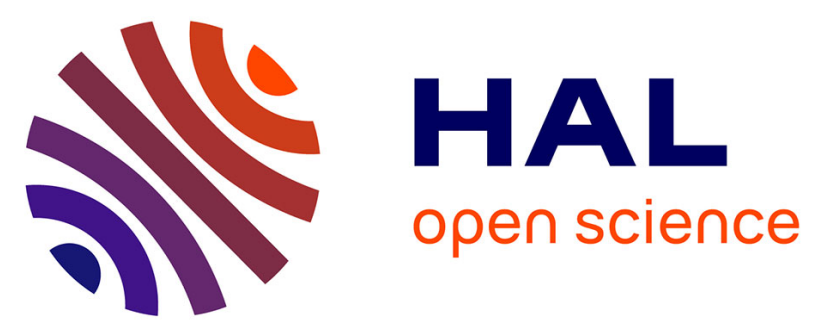

\title{
Turbulent burning characteristics of FACE-C gasoline and TPRF blend associated with the same RON at elevated pressures
}

O. Mannaa, Pierre Brequigny, Christine Mounaïm-Rousselle, Fabrice Foucher, S.H. Chung, W.L. Roberts

\section{To cite this version:}

O. Mannaa, Pierre Brequigny, Christine Mounaïm-Rousselle, Fabrice Foucher, S.H. Chung, et al.. Turbulent burning characteristics of FACE-C gasoline and TPRF blend associated with the same RON at elevated pressures. Experimental Thermal and Fluid Science, 2018, 95, pp.104-114. 10.1016/j.expthermflusci.2018.02.019 . hal-01934598

\section{HAL Id: hal-01934598 \\ https://hal.science/hal-01934598}

Submitted on 20 Mar 2019

HAL is a multi-disciplinary open access archive for the deposit and dissemination of scientific research documents, whether they are published or not. The documents may come from teaching and research institutions in France or abroad, or from public or private research centers.
L'archive ouverte pluridisciplinaire HAL, est destinée au dépôt et à la diffusion de documents scientifiques de niveau recherche, publiés ou non, émanant des établissements d'enseignement et de recherche français ou étrangers, des laboratoires publics ou privés. 


\title{
Turbulent Burning Characteristics of FACE gasoline and TPRF Blend Associated with the same RON at Elevated Pressures
}

\author{
O. Mannaa $^{1}$, P Brequigny ${ }^{2}$, C Mounaim-Rousselle ${ }^{2}$, F. Foucher ${ }^{2}$, \\ S. H. Chung ${ }^{1}$, W. L. Roberts ${ }^{1}$ \\ ${ }^{1}$ Clean Combustion Research Center, King Abdullah University of Science and Technology \\ Thuwal, Saudi Arabia \\ ${ }^{2} 2$ Laboratoire PRISME, Université d'Orléans, INSA CVL, Orléans 45072, France
}

\begin{abstract}
FACE-C gasoline/air and TPRF (51.6 vol. \% iso-octane, 21.5 vol.\% $n$-heptane and 26.9 vol.\% toluene)/air mixtures corresponding to the same RON of 85 were characterized in terms of determining their burning rates in a fan stirred turbulent vessel and filmed using high speed dual Schlieren imaging. Moreover, Mie scattering planar laser tomography was employed to characterize the variations of flame morphology induced by the coincident existence of different turbulent length scales and the susceptibility to develop cellular structures at elevated pressures (through the Darieus-Landau instability). Measurements were performed in a well-controlled environment of initial pressures $0.1,0.5$ and $1.0 \mathrm{MPa}$ at a fixed initial temperature of $358 \mathrm{k}$. These measurements were conducted at a range of measured turbulence intensities from 0.5 to $2.0 \mathrm{~m} / \mathrm{s}$. The enhancement of turbulent flame speed $S_{T}$ as a function of turbulent intensity was sized. The absence of bending regime was accounted for based on the size of the vessel and limited range of turbulent intensities investigated in the present work.
\end{abstract}

\section{Introduction}

The premixed combustion mode is often the preferred mode compared to nonpremixed combustion for a variety of considerations e.g., modern power and propulsion producing devices [1]. Moreover, as clearly emphasized in [2, 3], premixed turbulent combustion is inherently more complex than non- premixed turbulent combustion due to the strong coupling between chemistry and turbulence. Consequently, there have been various studies aiming to understand the governing parameters of such mode of combustion. One of the major assessment parameters for evaluating hydrocarbon premixed combustion is the flame speed. The one-dimensional adiabatic laminar is a physicochemical property of the mixture and initial combustion condition and is a metric for premixed combustion research and flame stability criteria. However, laminar flame speed does not incorporate the complexities associated with turbulence-chemistry interactions typical of practical combustion devices. As a result, another governing parameter known as turbulent burning velocity, $S_{\mathrm{T}}$, has been introduced to take into account the effects of turbulence intensity, mean flow velocity, and flow length scales on flame propagation speed. It has been fundamentally proven that $S_{\mathrm{T}}$ has a leading order impact on important combustor phenomenon such as the lifetime of hot section components, flashback and blowoff limits, and the operating limits before damaging combustion dynamic occurs [4]. This quantity is of considerable interest for theoretical investigation of turbulent flames and the influence of flame configuration on this quantity is essential for turbulent combustion modelling [5]. Similar to laminar flame speeds, turbulent flame speed can be integrated into various combustion models or for validation of detailed simulations [6].

One of the most adopted flame configurations for experimental investigations of turbulent premixed combustion is the outwardly propagating spherical flames. These flames are representative of flames in SI engines and has been advantageously employed to increase our understanding of mutual interaction between turbulence and unsteady flame propagation and also gain more insight regarding the ignition process [7].Furthermore, it is considered one 
of the favoured canonical configurations for measuring turbulent flame speed, $S_{\mathrm{T}}$. High pressure constant volume spherical combustion vessel can be a suitable choice to accommodate such flames geometry and to extend experimental conditions to engine-like conditions in terms of achieving high pressure, high temperature and high turbulence intensity simultaneously. Moreover, as shown in $[8,9]$, the proper design of such apparatus with multiple fans can promote the generation of reasonable Homogenous Isotropic Turbulence (HIT) in a zone located near the centre of the chamber where the mean flow is almost. This limit case of turbulence has been the cornerstone of multiple theoretical approaches as well as the building brick of Large eddy Simulation (LES) models [10, 11]. In fact, HIT is the only generic case where flame/turbulence mutual interaction can be investigated using a limited number of parameters[12, 13]. These experimental characteristics motivate the use of such configuration in the present study.

Gasoline fuels, composed of blends of hundreds of different hydrocarbons, vary in composition depending upon the source of crude oil from which it is made, the refining process used in its preparation, and seasonal factors. As a result, it is difficult to fairly conduct a quantitative comparison among experimental data with a high degree of certainty. In this regard, a well-designed matrix of Fuels for Advanced Combustion Engines (FACEs) was developed based on statistical methods targeting certain values, such as Research Octane numbers (RON) and fuel sensitivity (S) to accommodate high efficiency Advanced Combustion Engines [14]. The main advantage of utilizing research fuels is the ability to compare results obtained from different laboratories using the same set of fuels. Turbulent burning characterization of these fuels is indispensable to gain fundamental understanding about the combustion devices which they are fueled with. Accordingly, multi-component FACE-C gasoline corresponding to $\mathrm{RON} \approx 85$ was selected based on the merit of being well suited for the researchers to compare their results from different laboratories using the same type of fuel. To aid in kinetic mechanism development and combustion numerical simulations, a dramatically simplified fuel surrogate represented by a blend of ToluenePrimary Reference Fuel (TPRF-85) (51.6 vol. \% iso-octane, 21.5 vol.\% $n$-heptane and 26.9 vol.\% toluene) was also selected in this study to highlight the differences and similarities in the burning characteristics between fuels having the same RON, namely FACE-C gasoline and TPRF-85.

The main objective of this study is to rigorously characterize the turbulent flame propagation in terms of reporting $S_{\mathrm{T}}$ of both FACE-C gasoline and TPRF-85 over a wide range of turbulence intensity $\left(u^{\prime} \approx 0.5-2 \mathrm{~m} / \mathrm{s}\right)$ for different initial pressures of $0.1,0.5$ and 1.0 $\mathrm{MPa}$ and a fixed initial temperature of $358 \mathrm{~K}$. Moreover, the mutual interaction between flame front structures and turbulence will be quantitatively and qualitatively studied through Mie scattering imaging in order to gain further understanding regarding the link between flame structure and the turbulent flame propagation.

\section{Experimental Facility}

A spherically stainless steel combustion vessel with $200 \mathrm{~mm}$ inner diameter $(\approx 4.2$ liters) was employed to accommodate spherically expanding propagating flames. The apparatus can be used for studying both laminar and turbulent flame propagation. Below a brief description of the experimental setup integrated with its accessories and instrumentation devices is provided. More details are presented in [15].

The combustion chamber is capable of withstanding the peak temperature and pressures generated from deflagrations at initial pressure, $P o$, of up to $1.0 \mathrm{MPa}$ and initial temperatures, $T o$, of up to $473 \mathrm{~K}$. The liquid fuel is introduced through Coriolis mass flow meter (Bronkhorst mini CORI-FLOW $30 \mathrm{~g} / \mathrm{h}$ ) and the volume of air was introduced using thermal flow meters (Brooks 5850S, $2 \mathrm{NL} / \mathrm{min}$ for air, and $0.5 \mathrm{NL} / \mathrm{min}$ for nitrogen). The fuel/air mixture is centrally ignited using a spark produced between two oppositely aligned tungsten electrodes. The flame Kernel is initiated at the centre of the vessel and grows radially outwards. 
The vessel is equipped with multiple optical accesses through two orthogonal pairs of quartz windows of $60 \mathrm{~mm}$ diameter field of view and $40 \mathrm{~mm}$ thickness as depicted schematically in Fig.1. The vessel and the mixture are heated to temperature up to $358 \mathrm{~K}$ via a $3 \mathrm{KW}$ resistance heating wire embedded in the outer surface of the spherical vessel. During all measurements, the temperature fluctuations are kept within $2 \mathrm{~K}$ for the desired initial reactant temperature. Also the maximum deviation between reached and desired initial pressures is about $1 \%$.
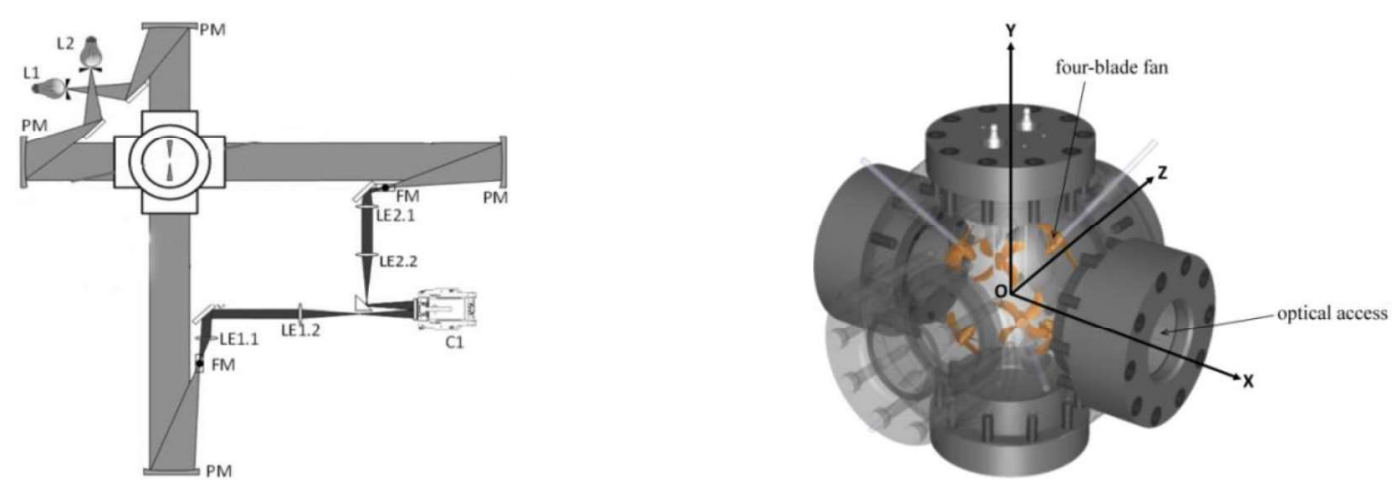

Figure. 1. (a) Schematic of the optical spherical combustion chamber with Dual Schlieren technique set-up(b) 3D drawing of fan-stirred vessel.

Turbulence is generated by six identical four-blade fans (diameter: $40 \mathrm{~mm}$, pitch: 36.5 $\mathrm{mm}$ ) located close to the wall in a regular octahedral configuration as shown in Fig.1b to create a central region of uniform, isotropic homogenous turbulence with negligible mean gas velocity as experimentally, verified in [16]. Creating a Homogenous and Isotropic Turbulent field (HIT) considerably simplifies the stochastic nature of turbulence. Each fan is coupled to a high RPM electric motor integrated with independent speed controller. Each fan speed was accurately adjustable between 1000 and $15000 \mathrm{rpm}$ within $\pm 0.1 \%$ of the target speed. The rotational direction of each fan results in blowing toward the centre of the vessel.

The chamber is optically accessible from front to back and from left to right (see Fig. 1b) which allows dual Schlieren images of centrally ignited, outwardly-propagating turbulent premixed flames at various conditions to be captured using a high speed camera (Phantom v1610) at full resolution $\left(1024 \times 800\right.$ pixels $\left.^{2}\right)$ with a magnification ratio of $0.11 \mathrm{~mm}$ per pixel. A scheme of the set-up is presented in Fig 1.a and fully describe in [17]. These sets of images were post-processed using an in-house developed MATLAB algorithm in order to temporally track the continuous growth of a propagating flame kernel. A second set of experiments were conducted using Mie scattering planar laser tomography in order to investigate quantitatively and qualitatively, the mutual interaction between the flame front dynamics and the coherent structures of turbulent length scales. Mie scattering images of propagating flame were captured through the scattering of silicon oil droplet from a laser sheet generated from a continuous laser (coherent Verdi. G15). The observed isotherm corresponding to the evaporation temperature of the silicon oil particles $(\sim 473 \mathrm{~K})$, enables the flame front boundary to be determined and morphologically examined.

\section{Data analysis on spherically propagating flame}

The analysis of turbulent spherical flame speeds began with the post-processing of , the 2D- light of sight Schlieren images shown in Fig.2, using an in-house MATLAB-based algorithm to trace the flame front boundaries The algorithm mainly tracks the 2D flame front spatial coordinates and calculates the burnt gas projection area within the turbulent flame kernel for each propagating flame. The enclosed area, $A(\mathrm{t})$, is then used to obtain the effective Schlieren flame radii via $R_{\mathrm{sch}}=\sqrt{A(t) / \pi}$. Due to an inherent asymmetry associated with each individual turbulent flame radius compounded by shot-to-shot variability of propagating 
turbulent kernel leading to greater data scattering, a mean effective flame radius $\left\langle R_{s c h}\right\rangle$ is derived for turbulent flame speed calculations.

\section{Results and discussion}

\subsection{Raw data and turbulent burning velocity}

Figure. 2 depicts a typical case of the temporal evolution of $\left\langle R_{s c h}(t)\right\rangle$ to explain how turbulent flame speed is estimated, for stoichiometric TPRF/air mixture at $358 \mathrm{~K}$ and three initial pressures $(1,5,10 \mathrm{~atm})$ under low $\left(u^{\prime}=0.5 \mathrm{~m} / \mathrm{s}\right)$ and high $\left(u^{\prime}=2.0 \mathrm{~m} / \mathrm{s}\right)$. The raw data of $\left\langle R_{s c h}(t)\right\rangle$ in Figs.2a and $2 \mathrm{c}$ are used to derive the turbulent flame speed Based on Equ. 1 :

$\mathrm{S}_{T}=0.9 \frac{\rho_{b}^{0}}{\rho_{u}^{0}} \frac{d\left\langle R_{s c h}\right\rangle}{d t}$

where $\frac{\rho_{b}^{0}}{\rho_{u}^{0}}$ is the thermal expansion ratio with $\rho_{u}^{0}$ and $\rho_{b}^{0}$ the unburned and burned gas density, respectively. The pre-multiplication factor (0.9) is Bradley's mean progress variable $\langle c\rangle$ converting factor when spherical flame geometries are measured by Schlieren [18].

This can be used in two ways as specified in [19]. The first one is to directly calculate the velocity by taking the time differentiation on $\left\langle R_{s c h}(t)\right\rangle$, while the second one is based on the determination of the slope for the best linear fit within $10 \mathrm{~mm} \leq\left\langle R_{s c h}(t)\right\rangle \leq 20 \mathrm{~mm}$. The requirement of $10 \mathrm{~mm} \leq\left\langle R_{s c h}(t)\right\rangle$ is to mitigate any influences of spark ignition. As can be also seen in Figs.2b and 2d, values of turbulent flame propagation speed, $S_{\mathrm{F}}$, to be determined not only represent the average of the near-linear (stable) increase data of $\mathrm{d}\left\langle R_{s c h}\right\rangle$, but also is equivalent to the local mean flame speed obtained via the $S F_{\text {,mean }}=$ $\frac{\int_{\left\langle R_{1}\right\rangle}^{\left\langle R_{2}\right\rangle}\left\langle R_{s c h}\right\rangle^{2} \frac{d\left\langle R_{s c h}\right\rangle}{d t} d\left\langle R_{s c h}\right\rangle}{\theta\left(\left\langle R_{S c h}\right\rangle_{2}^{3}-\left\langle R_{s c h}\right\rangle_{1}^{3}\right)}$, where $\theta$ is the thermal expansion ratio and $\left\langle R_{1}\right\rangle$ and $\left\langle R_{2}\right\rangle$ are 10 and $20 \mathrm{~mm}$ respectively. Noticeably, the standard error within $95 \%$ confidence interval increases as the turbulence intensity increases due to the higher experimental scattering associated with the high turbulence cases. Such an increase of data scattering springs from the drastic reduction of flame radii as the turbulence intensity increases. This can be attributed to either (1) a highly corrugated flame front or (2) a strong effect of turbulence on the ignition spark location, i.e. convected from the vessel centre by large eddies, which subsequently results in kernel displacement away from the imaging plane. At low turbulence intensities (e.g., $u^{\prime}=0.5 \mathrm{~m} / \mathrm{s}$ ) depicted in Fig.2b, as the pressure increases, the flame speed increases near a flame radius of $\left\langle R_{s c h}(t)\right\rangle \approx 20 \mathrm{~mm}$, close to the end boundary of HIT region of the vessel [16]. The noticeable increase of flame speed beyond $20 \mathrm{~mm}$ radius can be attributed to the accelerating mechanism leading to the full development of cellular structures due to the augmented hydrodynamic instability at elevated pressures. Furthermore, as will be elaborated later in detail, the low turbulence intensity effects are barely noticeable as the flame may not be subjected to the full spectrum of the desired turbulent intensity. On the other hand, for high turbulence intensity case $\left(e_{.} g_{.}, u^{\prime}=2.0 \mathrm{~m} / \mathrm{s}\right)$ in Fig. $2 \mathrm{~d}$, the enhancement in turbulent flame speed as the pressure increases is attributed to coupled effects between hydrodynamic instability and turbulent length scales altering the morphology of propagating flame front.

Figure. 4 shows the variations of $\mathrm{S}_{T}$ (left $\mathrm{Y}$-axis) which is determined using Eq. 1 for stoichiometric TPRF/air flames (a, b) and stoichiometric FACE-C/air flames (c, d) at $P_{o}$ of 0.1 and 1.0 MPa and $T_{0}=358 \mathrm{k}$ within the entire range of turbulence intensities examined in this study.The smallest flame kernel size (diameter) that provides reliable measurements is restricted to $20 \mathrm{~mm}$. Also, in order to capture the turbulent flame speed in the HIT regime and avoid any wall confinement effect, the largest flame kernel size (dimeter) is restricted to approximately to $40 \mathrm{~mm}$. 
Table 1 Laminar flame properties of TPRF and FACE-C at $\varphi=0.85 \& \varphi=1.0$ under three different pressures. Also values of different turbulent length scales over all investigated turbulence conditions are provided

\begin{tabular}{|c|c|c|c|c|c|c|c|c|c|c|c|c|}
\hline \multicolumn{13}{|c|}{ TPRF } \\
\hline \multicolumn{7}{|c|}{$\phi=0.85$} & \multicolumn{6}{|c|}{$\phi=1.0$} \\
\hline $\mathrm{P}_{\mathrm{o}}[\mathrm{atm}]$ & \multicolumn{2}{|l|}{1} & \multicolumn{2}{|c|}{5} & \multicolumn{2}{|c|}{10} & & 1 & \multicolumn{2}{|c|}{5} & \multicolumn{2}{|c|}{10} \\
\hline$\delta_{L}[\mathrm{~mm}]$ & \multicolumn{2}{|l|}{0.41} & \multicolumn{2}{|c|}{0.12} & \multicolumn{2}{|c|}{0.07} & & 0.36 & \multicolumn{2}{|c|}{0.11} & \multicolumn{2}{|c|}{0.06} \\
\hline$v\left[\mathrm{~m}^{2} / \mathrm{s}\right]$ & \multicolumn{2}{|l|}{$2.08 \times 10^{-5}$} & \multicolumn{2}{|c|}{$4.17 \times 10^{-6}$} & \multicolumn{2}{|c|}{$2.08 \times 10^{-6}$} & & $2.07 \times 10^{5}$ & \multicolumn{2}{|c|}{$4.14 \times 10^{-6}$} & \multicolumn{2}{|c|}{$2.07 \times 10^{-6}$} \\
\hline$\rho_{u}^{o} / \rho_{b}^{o}$ & \multicolumn{2}{|l|}{6.34} & \multicolumn{2}{|c|}{6.41} & \multicolumn{2}{|c|}{6.43} & & 6.86 & \multicolumn{2}{|c|}{6.98} & \multicolumn{2}{|c|}{7.02} \\
\hline$S_{L}^{o}[\mathrm{~m} / \mathrm{s}]$ & \multicolumn{2}{|l|}{0.39} & \multicolumn{2}{|c|}{0.25} & \multicolumn{2}{|c|}{0.19} & & 0.45 & \multicolumn{2}{|c|}{0.29} & \multicolumn{2}{|c|}{0.23} \\
\hline & & & & & & CE-C & & & & & & \\
\hline \multicolumn{7}{|c|}{$\phi=0.85$} & & & \multicolumn{2}{|c|}{$\phi=1.0$} & & \\
\hline $\mathrm{P}_{\mathrm{o}}[\mathrm{atm}]$ & \multicolumn{2}{|l|}{1} & \multicolumn{2}{|c|}{5} & \multicolumn{2}{|c|}{10} & & 1 & & & & \\
\hline$\delta_{L}[\mathrm{~mm}]$ & 0.40 & & 0. & & & 09 & & 0.33 & & & & \\
\hline$v\left[\mathrm{~m}^{2} / \mathrm{s}\right]$ & $2.08 \times 10$ & & 4.17 & & & $\times 10^{-6}$ & & $2.07 \times 10^{5}$ & 4.12 & $10^{-6}$ & 2.07 & $10^{-6}$ \\
\hline$\rho_{u}^{o} / \rho_{b}^{o}$ & 6.33 & & 6.3 & & & 40 & & $\begin{array}{l}6.80 \\
\end{array}$ & & & & \\
\hline$S_{L}^{o}[\mathrm{~m} / \mathrm{s}]$ & 0.38 & & 0.2 & & & 22 & & 0.44 & & & & \\
\hline $\mathrm{P}_{\mathrm{o}}[\mathrm{atm}]$ & & & & & & 5 & & & & 1 & & \\
\hline $\mathrm{u}^{\prime}[\mathrm{m} / \mathrm{s}]$ & 0.5 & 1 & 1.5 & 2 & 0.5 & 1 & 1.5 & 2 & 0.5 & 1 & 1.5 & 2 \\
\hline $\mathrm{L}_{\mathrm{T}}[\mathrm{mm}]$ & 3.4 & 3.4 & 3.4 & 3.4 & 3.4 & 3.4 & 3.4 & 3.4 & 3.4 & 3.4 & 3.4 & 3.4 \\
\hline$\lambda[\mathrm{mm}]$ & 1.45 & 1.03 & 0.84 & 0.72 & 0.65 & 0.46 & 0.37 & 0.32 & 0.46 & 0.32 & 0.26 & 0.23 \\
\hline $10 \eta[\mathrm{mm}]$ & 1.23 & 0.75 & 0.53 & 0.43 & 0.36 & 0.26 & 0.21 & 0.18 & 0.21 & 0.15 & 0.12 & 0.11 \\
\hline
\end{tabular}

It is clearly shown in Fig.4 that the flame speeds increase as the turbulent flames expand, especially in the case of higher turbulence intensities. Several physical mechanisms have been proposed in the literature to account for such accelerating behaviour [20,21].

These mechanisms can be summarised in just three main ones:

- First, the gas expansion mechanism due to flame front. But it was numerically shown in [21] that integral scale size eddies are sufficiently strong to suppress the gas-dynamic instabilities induced by thermal expansion at the smaller scales.

-Second, the effective turbulent intensity level experienced by the flame is the combined effect of turbulence generated by fans and combustion induced turbulence. Nevertheless, such effect was only validated over a narrow range of experimental conditions [22] and cannot be generalized.

Third, Bradley et al. [23, 24] experimentally developed a widely accepted theory to explain the accelerating nature of turbulent flame. The idea is that the developing flame kernel is not perturbed by the entire spectrum of eddies. The initial flame kernel, growing from a point source is affected by smaller eddies than the flame diameter, inducing flame wrinkling. On the other hand, larger eddies simply induce the convection of the flame front like a passive surface. The spectrum theory has mathematically derived an effective turbulent intensity level experienced by the expanding flame by integrating the non-dimensional spectral density function expressed as

$$
\bar{S}\left(\overline{k_{\eta}}\right)=\frac{0.01668 R e_{\lambda}^{2.5}+3.74 R e_{\lambda}^{0.9}-70 R e_{\lambda}^{-0.1}}{1+\left(0.127 R e_{\lambda}^{1.5} \overline{k_{\eta}}\right)^{5 / 3}+\left(1.15 R e_{\lambda}^{0.622} \overline{k_{\eta}}\right)^{4}+\left(1.27 R e_{\lambda}^{0.357} \overline{k_{\eta}}\right)^{7}}
$$

Where $R_{\lambda}$ is the Taylor-scale-based Reynolds number that can be estimated from the turbulent Reynolds number (based on the integral length scale $\mathrm{L}_{\mathrm{T}}$ ) using $R_{\lambda}=4 R e_{T}{ }^{0.5}$ and $\overline{k_{\eta}}$ is the dimensionless wavenumber obtained by multiplying $2 \pi$ /wavelength with the Kolmogorov length scale, $\eta$. The effective rms turbulent velocity $\left(u_{k}^{\prime}\right)$ acting on the flame can then be obtained as,

$$
\frac{u_{k}^{\prime}}{u^{\prime}}=\left[\frac{\sqrt{15}}{R_{\lambda}} \cdot \int \frac{\overline{k_{\eta 2}}}{k_{\eta 1}} \bar{S}\left(\overline{k_{\eta}}\right) d \overline{k_{\eta}}\right]^{0.5}
$$

where, $\overline{k_{\eta 1}}$ is the lower cut-off wavenumber based on the flame diameter and $\overline{k_{\eta 2}}$ is the upper cut-off wavenumber based on the Gibson scale [25]. 

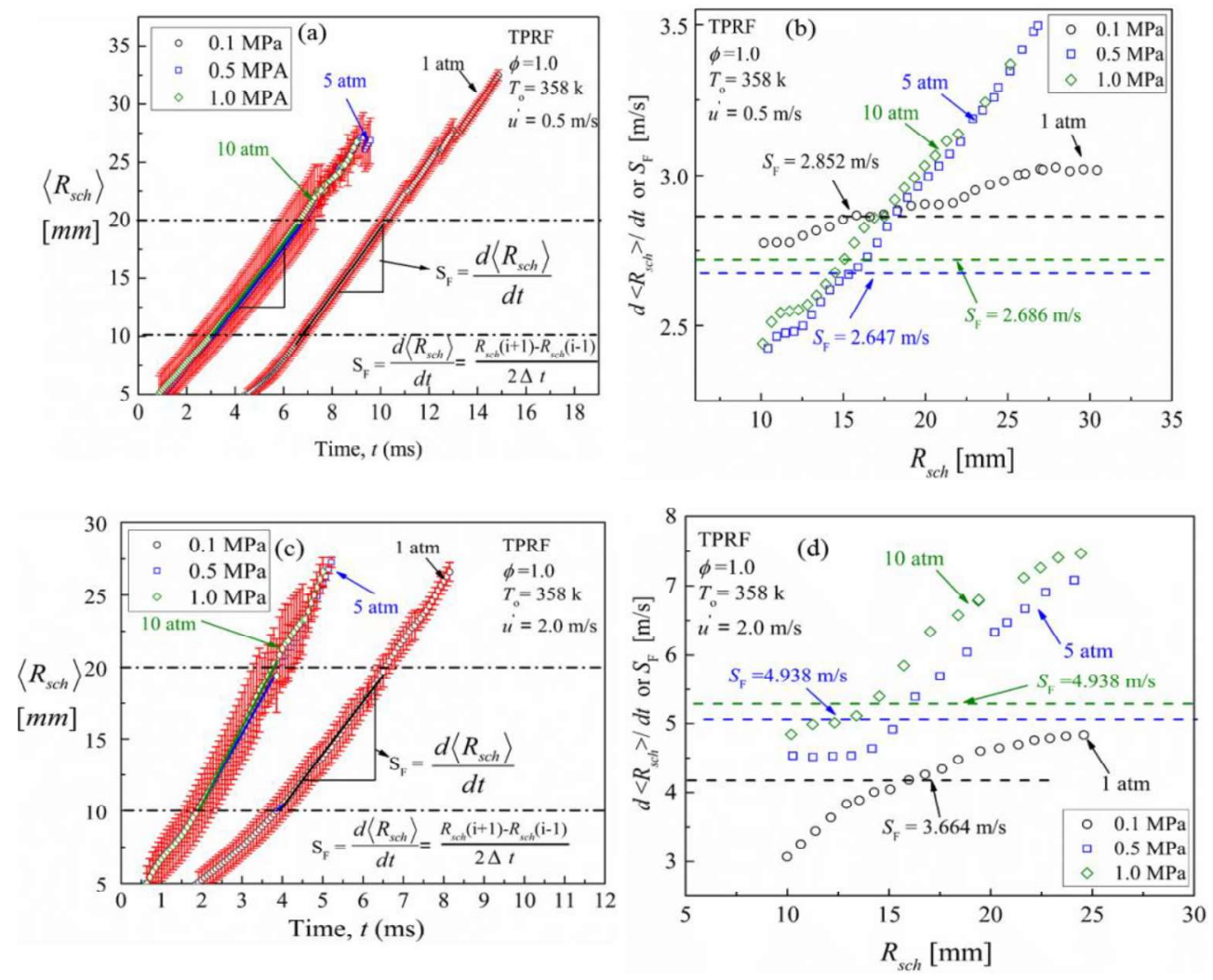

Figure. 2. Temporal evolution of averaged flame radii for stoichiometric TPRF at three different initial pressures $(1,5,10 \mathrm{~atm})$ at (a) low turbulence intensity $\left(u^{\prime}=0.5 \mathrm{~m} / \mathrm{s}\right)$ and (c) high turbulence intensity $\left(u^{\prime}=2.0 \mathrm{~m} / \mathrm{s}\right)$. Two turbulent flame speeds, namely $S_{\mathrm{F}}$ determined within $10 \mathrm{~mm}<\left\langle R_{\text {sch }}\right\rangle<20 \mathrm{~mm}$ and $\frac{d\left\langle R_{s c h}\right\rangle}{d t}$, as indicated in (b) and (d) plotted against $R_{\text {sch }}$ and correspond to $u^{\prime}=0.5$ and $2.0 \mathrm{~m} / \mathrm{s}$, respectively.

The effective r.m.s turbulent velocity, $u_{k}^{\prime}$, is less than $u^{\prime}$ measured in the vessel without any flame. The variations of $u_{k}^{\prime}$ as function of the flame kernel expansion are plotted in Fig.3 on the right $y$-axis (illustrated by dashed lines. It should be noted that the propagating flame may not experience the full spectrum of turbulent intensity during the usable part of the experiment (when the flame kernel size closely matches the viewing window size $\cong 6 \mathrm{~cm}$ dimeter).

For both operating initial pressures, $\mathrm{S}_{\mathrm{T}}$ increases as the flame grows due to the aforementioned spectrum theory that the developing kernel is affected by an increasing spectrum of eddies scales.

Thus the canonical configuration of a spherically expanding flame vessel provides turbulent flame speed over a wide range of $u^{\prime}$ in a single shot. Noticeably, as shown in Figs $3 \mathrm{a}$ and $3 \mathrm{c}$, for atmospheric flames the turbulent burning velocities for both fuels increase nonmonotonically as the turbulence intensity increases. Indeed, as the turbulence intensity increases, both the Taylor microscale $\lambda$ and Kolmogorov length scales $\eta$ decreases (see table. 1) which result in inducing more corrugation of the flame front and thus increasing the burning rate. In other words, due to the fixation of integral length scale by the geometrical dimensions of the facility, increasing the Reynolds number (i.e., increasing the rotational fan speed) causes the generation of finer local dissipation scales. On the other hand, for $10 \mathrm{~atm}$ flames transiting from relatively high to high turbulence intensities $\left(u^{\prime}=1.5\right.$ to, $\left.2.0 \mathrm{~m} / \mathrm{s}\right)$ shown in Figs $3 b$ and $3 d$, the Taylor microscale $\lambda$ and Kolmogorov length scales $\eta$ level off as the pressure increases (see table.1) [16] which do not contribute in generating more wrinkling of the flame front and in turn no more increase in the turbulent flame speed. 


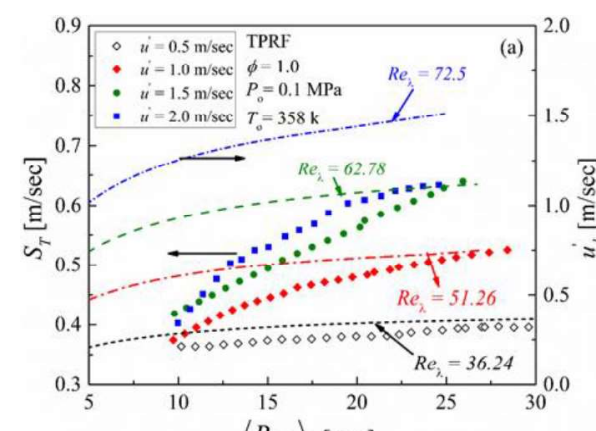

$\left\langle R_{S c h}\right\rangle[\mathrm{mm}]$
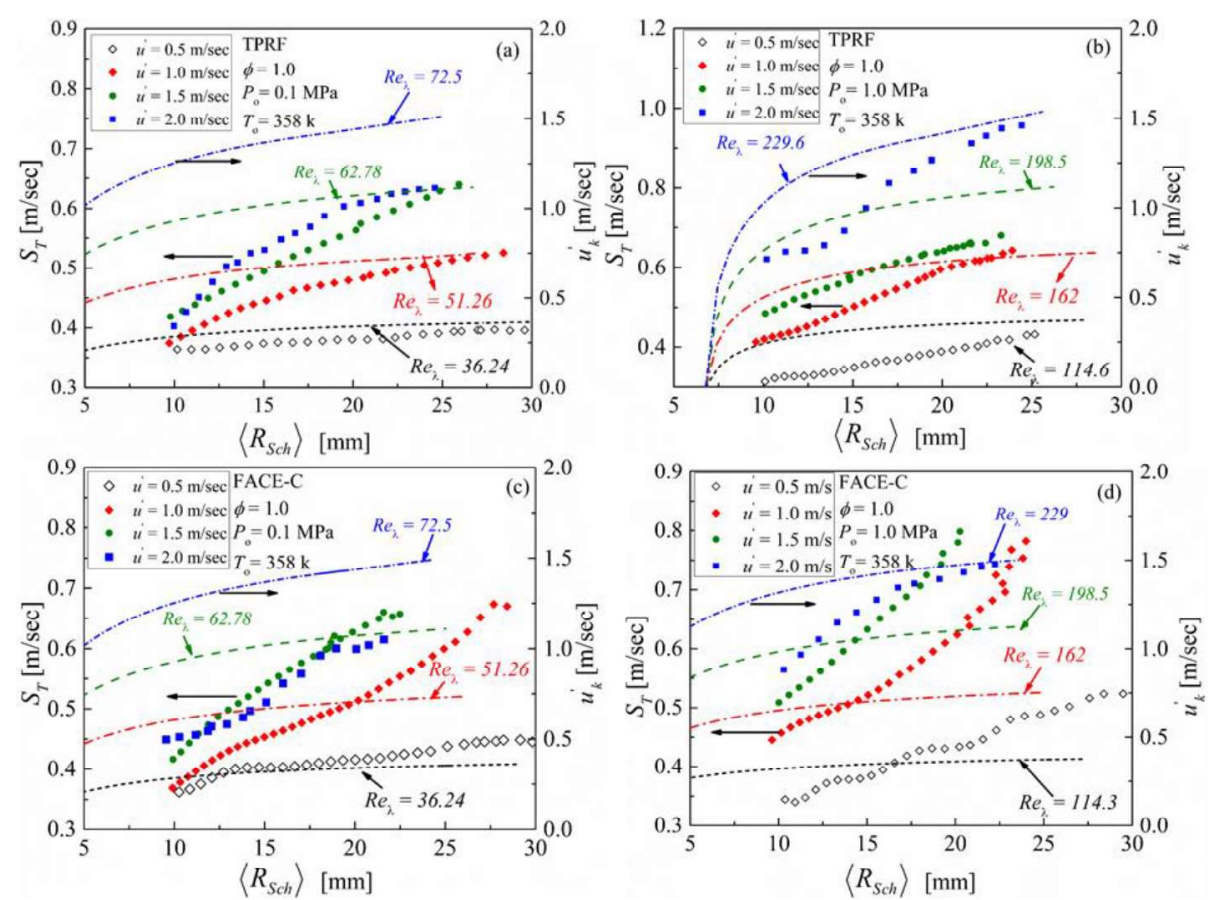

Figure. 3. Variations of turbulent flame speeds, $S_{T}$, estimated using eq.1 as a function of averaged Schlieren flame radii $\left\langle R_{s c h}\right\rangle$ for stoichiometric TPRF $(\mathrm{a}, \mathrm{b})$ and FACE-C gasoline (c, d) flames for wide range of turbulence intensities, $u^{\prime}$, at $1 \mathrm{~atm}$ and $10 \mathrm{~atm}$, respectively and fixed initial temperature of $T_{\mathrm{o}}=358 \mathrm{k}$.

However, at high pressure the flame speed of outwardly propagating flame front increases continuously due to the early development of a full cellular structure across the flame front resulting in a significant flame front area increase.

Figure. 4 presents the variations of normalized turbulent flames speeds, $\frac{S_{T}}{S_{L}^{0}}$, versus the normalized turbulent intensity, $\frac{u^{\prime}}{s_{L}^{0}}$, over a three different initial pressures $(1,5,10 \mathrm{~atm})$ for lean (a, c) and stoichiometric (b, d) TPRF/air and FACE-C /air mixtures, respectively. Clearly, equivalence ratio of the mixture plays a critical role in terms of the response of turbulent flame speed to different turbulence intensity levels, experienced by the propagation flame front. $S_{\mathrm{T}}$ for lean atmospheric TPRF/air and FACE-C /air mixture exhibits insignificant enhancement at all tested turbulent intensities. For high pressure flames, the turbulent flame speeds do not clearly manifest the bending effect behaviour as function of the turbulent intensity. This mainly can be attributed to the relative small size of the vessel and the observed flames which in turn result in narrowing the range of effective turbulent intensity, $u_{k}^{\prime}$, acting on the propagating flame kernel.

One of the most controversial aspects in premixed turbulent flames is the effect of pressure on $S_{\mathrm{T}}$. Kobayashi et al [26] had experimentally shown the enhancement of $S_{\mathrm{T}}$ as the pressure increases. They explained such increases based on the decrease in mixture thermaldiffusivity which in turn promotes flame-instability through a subsequent reduction in flame thickness. On the other hand, Lie et al [19] simply suggested that any enhancement of turbulent flame speed with pressure is merely a manifestation of enhancement of turbulent Reynolds number $\left(\mathrm{Re}_{\mathrm{T}}\right)$ with pressure due to the decreasing $v$ at elevated pressure because $v \sim \rho^{-1} \sim P^{-1}$. Therefore, they were able to show the decrease of $\mathrm{S}_{\mathrm{T}}$ with pressure similar to laminar flame speed at constant Reynolds number in a fan stirred bomb.

Consequently, one of main objectives of this study is to highlight the effect of pressure on $S_{\mathrm{T}}$ for two different fuels at two different air/fuel ratios, as plotted in Fig. 5. For both fuels, at low $u^{\prime}, S_{\mathrm{T}}$ barely shows any enhancement if not reduction. On the other hand, at moderate and high turbulence intensities, $S_{\mathrm{T}}$ noticeably increases as the pressure increases, most of the cases up to $P_{0}=0.5 \mathrm{MPa}$. With the increase in pressure, the flame thickness is reduced (smallscale effect) 

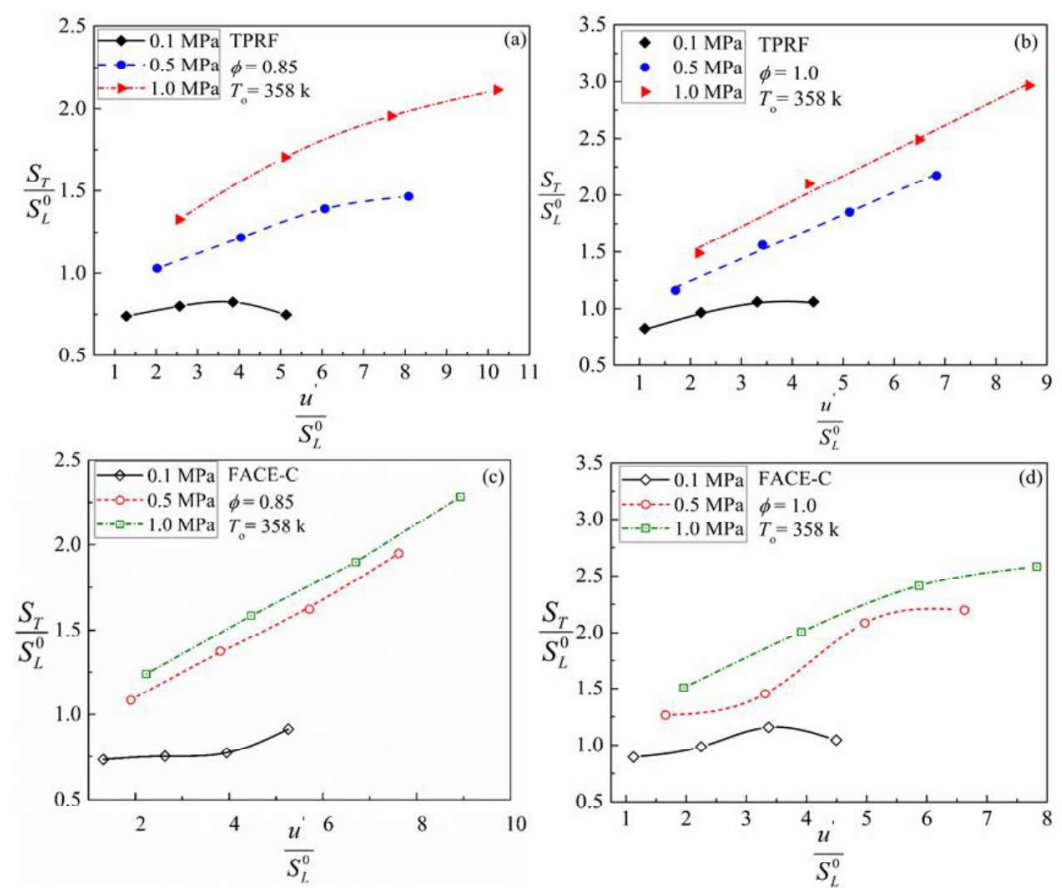

Figure. 4. Variations of normalized turbulent flame speeds as a function of turbulent intensity for three different initial pressures $(1,5,10 \mathrm{~atm})$ for (a) lean TPRF/air mixture $(\phi=0.85)$, (b) Stoichiometric TPRF/air mixture $(\phi=1.0)$, (c) lean FACE-C/air mixture $(\phi=0.85)$ and (d) stoichiometric FACEC/air mixture $(\phi=1.0)$

which leads to extension of the flame surface dissipation spectrum to higher wavenumbers turbulent length scales. At elevated pressures higher wave numbers (smaller turbulent length scale) are now accessible for turbulent wrinkling which increases flame front surface area and thus the burning rate.

As previously point out, as the pressure increases up to $P_{\mathrm{o}}=1.0 \mathrm{MPa}$, the enhancement in turbulent flame speeds at moderate and high turbulent intensities nearly exhibit either a plateau as shown in Figs $5 \mathrm{a}$ and $5 \mathrm{~b}$ or a slight decrease as shown in Figs $5 \mathrm{c}$ and $5 \mathrm{~d}$. This can be attributed to the levelling off of highest length scales[16], namely Taylor and Kolmogorov ones which limit the turbulent wrinkling of the flame front at elevated pressures, particularly at $1.0 \mathrm{MPa}$.

\subsection{Flame Growth and Morphology characterises}

In order to highlight the coupling between turbulence intensity and the inherent Darrieus-Landau flame instability and their effect on flame morphology, planar Mie scattering images of turbulent flame front were also recorded. The tomographic images typically present a clear contrast which makes it possible to extract flame boundary as the interface between the dark and light areas corresponding to the burned and unburned gases respectively.

Figure. 6 depicts the temporal evolution of flame contours for both (a) TPRF and (b) FACE-C gasoline at 1 and 5 atm in the case of low and moderate turbulent intensities. For experiments with planar Mie scattering tomography, the turbulent intensity levels were limited to avoid one of the most important sources of biases due to the displacement of the centre of the flame kernel out of the plane of the laser sheet during the flame propagation. As shown in Fig.6, the flame contours are well centered and superimposed as function of time. Qualitatively, the flame contours presented in Fig. 6 underline the response of flame front to the mutual interaction between flame dynamics and turbulence effects in terms of length scales and turbulence intensity by wrinkling and corrugating the flame front. 

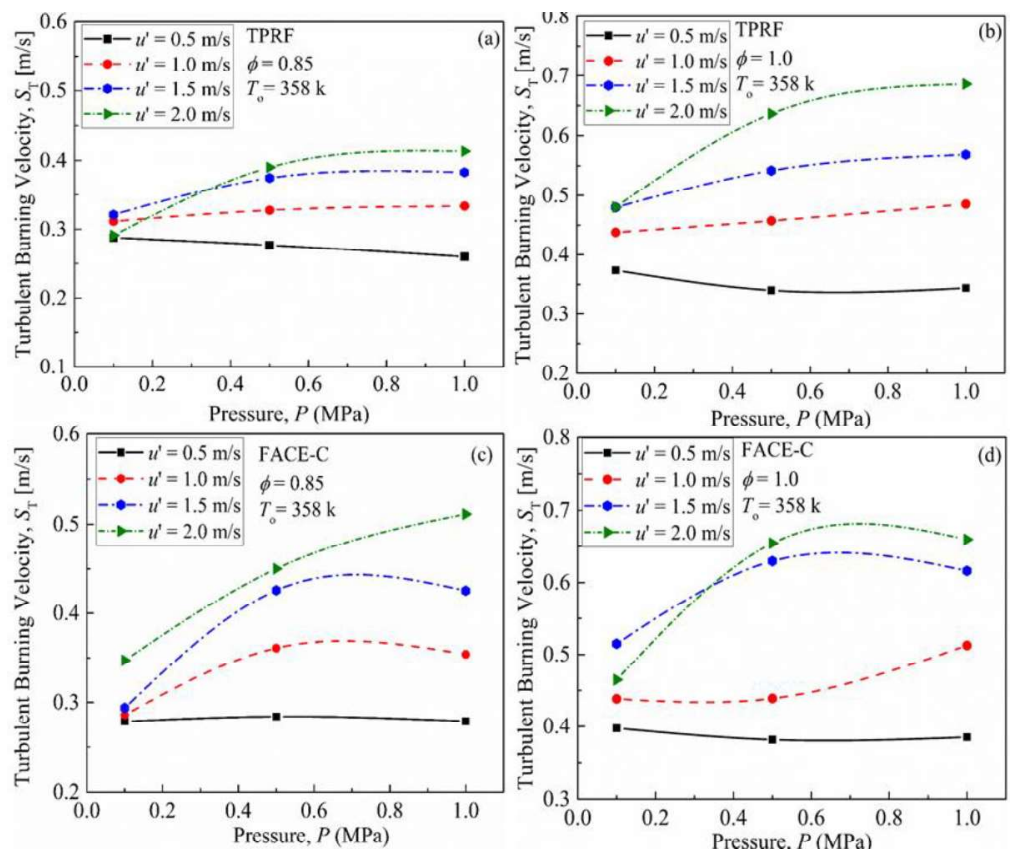

Figure. 5. Effect of initial pressure on turbulent burning velocities for all turbulent intensity levels $\left(u^{\prime}\right.$ $=0.5-2 \mathrm{~m} / \mathrm{s})$ for (a) lean TPRF/air mixture $(\phi=0.85)$, (b) Stoichiometric TPRF/air mixture $(\phi=1.0)$,

(c) lean FACE-C/air mixture $(\phi=0.85)$ and (d) stoichiometric FACE-C/air mixture $(\phi=1.0)$

At the lowest turbulence intensity $\left(u^{\prime}=0.5 \mathrm{~m} . / \mathrm{s}\right)$, atmospheric flames for both TPRF/air and FACE-C gasoline/ air mixtures nearly grow in a quasi-spherical manner without any significant contour distortion, at least within the limits of the initial flame development.

Noticeably, for both low and moderate turbulence conditions, the flame kernels is globally laminar and probably any initial ridges or bulges across the flame front can be due ignition electrode induced perturbations, particularly for atmospheric flames.

Clearly, as shown in Fig. 6, as the turbulence increases, the amplitude and the spatial frequency of the flame wrinkles strongly increase. As the flame size becomes greater than that of the largest turbulence structure represented by the integral length scale, flame wrinkling starts to appear due to the mutual interaction between the propagating of flame front and local flow field close to it $[27,28]$. Noticeably, as depicted in Fig.6, for all the tested cases, after a certain time of development, the propagating flame front reaches one geometry shape and keeps it with temporal evolution. For high pressure flames, particularly at moderate turbulence intensity the combined effects of high $u^{\prime}$ and the tendency of a flame to develop cellular structures at high pressure promote the apparition of high wavenumbers fine structure (ridges) across the flame front. This is mostly due to the subsequent reduction of laminar flamelet thickness with pressure which allows flame surface wrinkling at progressively smaller scales.

Numerous geometrical data can be extracted from the flame contour obtained via Mie scattering imaging. For turbulent premixed flame, the variations of combustion rate can be directly linked to the increase of flame front surface area. Such variation can result simultaneously from the temporal evolution of the mean flame size and the flame wrinkling produced by the coherent turbulent structure of the flow-field. The flame wrinkling degree can be characterized by the so-called wrinkling factor, W, defined by Renou and Boukhalfa $[27,28]$ and mathematically expressed as :

$$
\mathrm{W}=\frac{R_{P}^{2}}{R_{S}^{2}}
$$




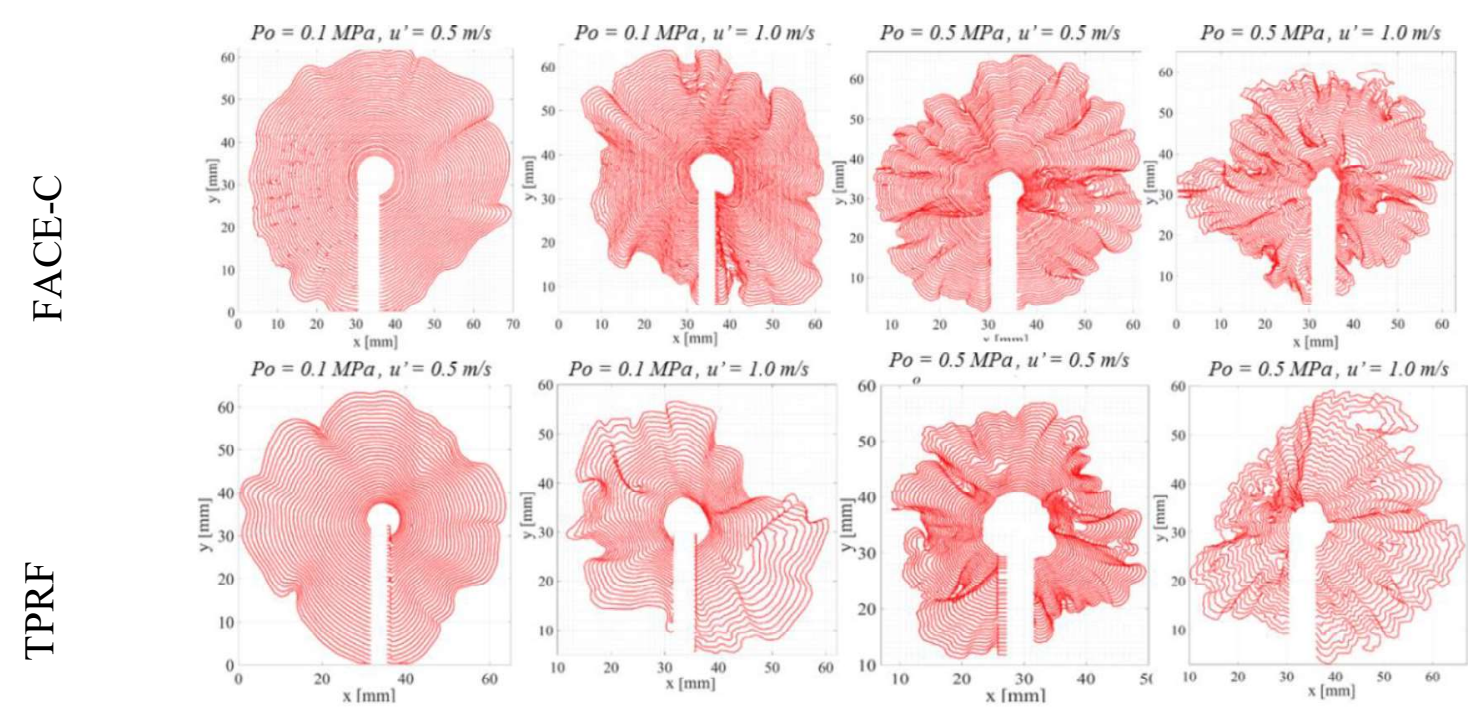

Figure. 6. Temporal evolution of turbulent flame fronts for both stoichiometric FACE-C gasoline/air mixture (first row) and TPRF/air mixture (second row) at low $\left(u^{\prime}=0.5 \mathrm{~m} / \mathrm{s}\right)$ and moderate $\left(u^{\prime}=2\right.$ $\mathrm{m} / \mathrm{s}$ ) turbulent intensity for two different initial pressures ( 1 and $5 \mathrm{~atm}$ )

Where $R_{\mathrm{s}}$ is flame radius deduced for the instantaneous flame surface area which represents the area of burned gases engulfed by the flame surface and delimited by the laser sheet and $R_{\mathrm{P}}$ the flame radius derived from the flame perimeter computed from the flame contour. The wrinkling ratio characterizes the degree of flame wrinkling which affects the burning rate. The wrinkling factor takes into account several effects: the smoothing out of the flame wrinkles due to Huygen's effects, the effect of kinematic viscosity variations in the flame front on the strain rate, the density variation effects on both the strain rate and the structural feature of turbulence in the fresh gases, and the dilatation of flame front due to the thermal expansion of gases[27].

The temporal evolution of the wrinkling ratio is plotted in Fig.7 for both stoichiometric FACE-C/air and TPRF /air flames at low and moderate turbulence intensity and at atmospheric and $0.5 \mathrm{MPa}$ pressures. For atmospheric flames at low turbulence intensity $\left(u^{\prime}=\right.$ $0.5 \mathrm{~m} . / \mathrm{s})$, the wrinkling ratio is quasi-constant and slightly larger than unity, as can be seen in Fig.8. Either as the pressure or the turbulent intensity levels increases, the wrinkling ratio exhibits a noticeable increase versus the temporal evolution of the surface equivalent radii, $R_{\mathrm{s}}$.

Flame Curvature is also another indicative parameter of the response of the flame front to the turbulent flow fields, which provides physical insight about the influence of flame shape on flamelet burning. Shown in Fig. 8 are the pdfs of curvature for stoichiometric TPRF-air and FACE-C-air mixtures at initial temperature of $358 \mathrm{~K}$ and initial pressures of 0.1 and $0.5 \mathrm{MPa}$ under the effect of low $\left(u^{\prime}=0.5 \mathrm{~m} / \mathrm{s}\right)$ and moderate $\left(u^{\prime} 1.0 \mathrm{~m} / \mathrm{s}\right)$ turbulence intensity. All the pdfs are nearly symmetric with a Gaussian-like distribution. For atmospheric flames, the width of pdfs (variance) increases with increase in $u^{\prime}$, commensurate with increased flame wrinkling. Such trend is barely noticeable for high pressure flames $\left(P_{\mathrm{o}}=0.5 \mathrm{MPa}\right)$. Also, in particular for atmospheric flames, pdfs of TPRF-air mixtures show to some extent a wider width compared to their counterparts of FACE-C- gasoline-air mixture. 


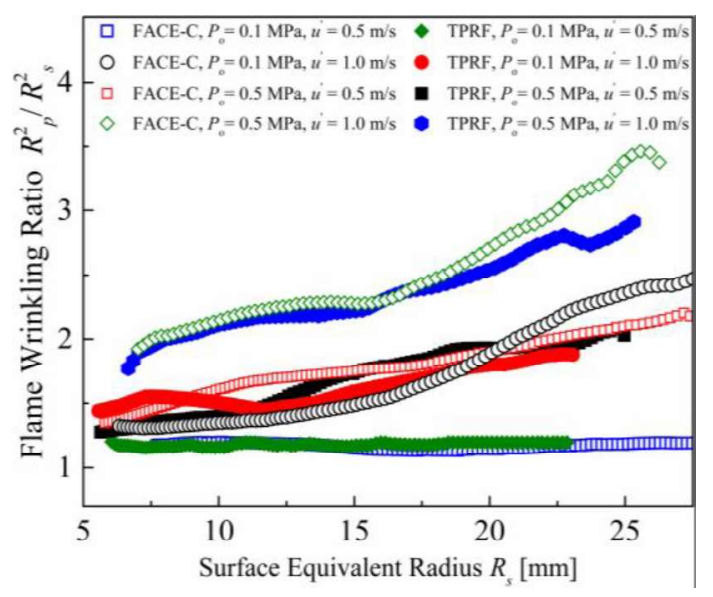

Figure. 7. Temporal evolution of the wrinkling ratio, $\mathrm{W}$, versus the surface equivalent radius, $\mathrm{R}_{\mathrm{s}}$ for stoichiometric TPRF/air and FACE-C gasoline/air flames for low $\left(u^{\prime}=0.5 \mathrm{~m} / \mathrm{s}\right)$ and moderate $\left(u^{\prime}=\right.$ $1.0 \mathrm{~m} / \mathrm{s}$ ) turbulence intensities at two different initial pressures ( 1 and $5 \mathrm{~atm})$
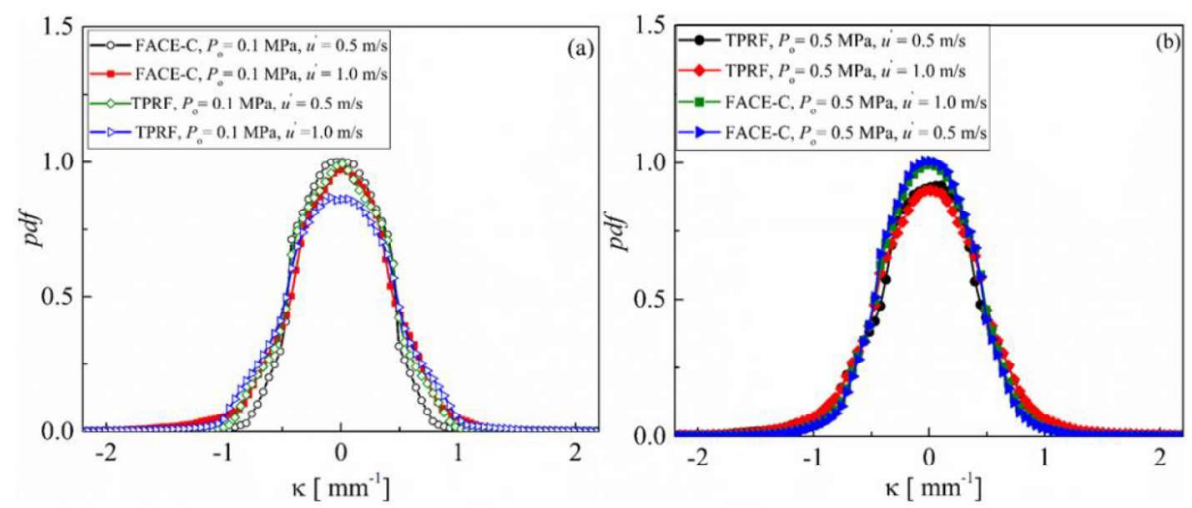

Figure.8. pdfs of curvature for stoichiometric TPRF and FACE-C at low moderate $\left(u^{\prime}=0.5 \mathrm{~m} / \mathrm{s}\right)$ and moderate $\left(u^{\prime}=1.0 \mathrm{~m} / \mathrm{s}\right)$ turbulence intensity at (a) $P_{\mathrm{o}}=0.1 \mathrm{MPa}$ and (b) $P_{\mathrm{o}}=0.5 \mathrm{MPa}$

\section{Conclusion}

The present study aims to measure turbulent flame speeds of two different fuels at elevated pressures and relatively wide range of turbulent intensities. Lean $(\phi=0.85)$ and stoichiometric ( $\phi=1.0)$ mixtures were tested to emphasize the enhancement of $S_{\mathrm{T}}$ associated with mixtures characterized by different laminar burning velocities. FACE-C gasoline has a relatively higher $S_{\mathrm{T}}$ at high turbulent intensity than TPRF. At low turbulence intensity, $S_{\mathrm{T}}$ shows no enhancement with the pressure increase but occasionally exhibits a similar behavior corresponding to variation of laminar burning velocities with pressure. For moderate and high turbulence intensities, the enhancement of $S_{\mathrm{T}}$ for both fuels as a function of the pressure increase has shown a non-monotonic behavior due to the competing effect between promoting flame cellularity and reducing effective turbulent intensity, $u_{k}^{\prime}$, and laminar flame speed at high pressures. Future studies are needed to understand better the variant effect of pressure on turbulent flame speed of outwardly propagating turbulent. Also these studies should highlight the influence on turbulent burning velocities by altering the mutual interaction between flame's internal chemistry and time varying stretch rate at leading points of flame kernel. Qualitative and quantitative analyses of planar Mie scattering images of the flame front reveal the fine structures of flame wrinkling triggered by the simultaneous existence of various turbulent length scale and the cellular structure augmented by the promoted hydrodynamic instability at elevated pressure. Based on pdf distribution of the curvature values, TPRF-air mixtures show, to some extent, more fine structures compared to FACE-C gasoline-air mixture. 


\section{References.}

[1] J. M. Beér, "Combustion technology developments in power generation in response to environmental challenges," Progress in Energy and Combustion Science, vol. 26, pp. 301-327, 2000.

[2] R. Bilger, S. Pope, K. Bray, and J. Driscoll, "Paradigms in turbulent combustion research," Proceedings of the Combustion Institute, vol. 30, pp. 21-42, 2005.

[3] R. Bilger, "Future progress in turbulent combustion research," Progress in energy and combustion science, vol. 26, pp. 367-380, 2000.

[4] T. Lieuwen, V. McDonell, E. Petersen, and D. Santavicca, "Fuel flexibility influences on premixed combustor blowout, flashback, autoignition, and stability," Journal of engineering for gas turbines and power, vol. 130, p. 011506, 2008.

[5] J. F. Driscoll, "Turbulent premixed combustion: Flamelet structure and its effect on turbulent burning velocities," Progress in Energy and Combustion Science, vol. 34, pp. 91-134, 2008.

[6] I. Walters, "Effects of Dilution on Turbulent Consumption Speeds of Jet Fuel," 2016.

[7] S. Shy, W. Shih, and C. Liu, "More on minimum ignition energy transition for lean premixed turbulent methane combustion in flamelet and distributed regimes," Combustion Science and Technology, vol. 180, pp. 1735-1747, 2008.

[8] P. Laffitte, "La propagation des flammes dans les mélanges gazeux, Hermann et Cie," Actualités scientifiques et industrielles, PARIS, 1939.

[9] E. Semenov, "Measurement of turbulence characteristics in a closed volume with artificial turbulence," Combustion, Explosion, and Shock Waves, vol. 1, pp. 57-62, 1965.

[10] E. Lenormand, P. Sagaut, L. T. Phuoc, and P. Comte, "Subgrid-scale models for large-eddy simulations of compressible wall bounded flows," AIAA journal, vol. 38, pp. 1340-1350, 2000.

[11] P. Moin, K. Squires, W. Cabot, and S. Lee, "A dynamic subgrid-scale model for compressible turbulence and scalar transport," Physics of Fluids A: Fluid Dynamics, vol. 3, pp. 2746-2757, 1991.

[12] T. Poinsot and D. Veynante, Theoretical and numerical combustion: RT Edwards, Inc., 2005.

[13] N. Peters, "Turbulent Combustion Cambridge University Press," Cambridge, UK, p. 95, 2000.

[14] W. Cannella, M. Foster, G. Gunter, and W. Leppard, "FACE gasolines and blends with ethanol: detailed characterization of physical and chemical properties," CRC Report No AVFL-24, 2014.

[15] B. Galmiche, F. Halter, and F. Foucher, "Effects of high pressure, high temperature and dilution on laminar burning velocities and Markstein lengths of iso-octane/air mixtures," Combustion and Flame, vol. 159, pp. 3286-3299, 2012.

[16] B. Galmiche, N. Mazellier, F. Halter, and F. Foucher, "Turbulence characterization of a high-pressure high-temperature fan-stirred combustion vessel using LDV, PIV and TR-PIV measurements," Experiments in fluids, vol. 55, p. 1636, 2014.

[17] P. Schiffmann, V. Sick, and F. Foucher, "Multi-diagnostics Analysis of Flow Induced Combustion Variability at SI Engine-Like Conditions."

[18] D. Bradley, M. Lawes, and M. Mansour, "Correlation of turbulent burning velocities of ethanol-air, measured in a fan-stirred bomb up to 1.2 MPa," Combustion and Flame, vol. 158, pp. 123-138, 2011.

[19] C.-C. Liu, S. S. Shy, M.-W. Peng, C.-W. Chiu, and Y.-C. Dong, "High-pressure burning velocities measurements for centrally-ignited premixed methane/air flames interacting with intense near-isotropic turbulence at constant Reynolds numbers," Combustion and Flame, vol. 159, pp. 2608-2619, 2012.

[20] W. T. Ashurst, "A simple illustration of turbulent flame ball growth," Combustion science and technology, vol. 104, pp. 19-32, 1995.

[21] N. Peters, H. Wenzel, and F. Williams, "Modification of the turbulent burning velocity by gas expansion," Proceedings of the Combustion Institute, vol. 28, pp. 235-243, 2000.

[22] B. Leisenheimer and W. Leuckel, "Self-Generated Acceleration of Confined Deflagrative Flame Fronts*," Combustion science and technology, vol. 118, pp. 147-164, 1996.

[23] R. Abdel-Gayed, D. Bradley, and M. Lawes, "Turbulent burning velocities: a general correlation in terms of straining rates," in Proceedings of the Royal Society of London A: Mathematical, Physical and Engineering Sciences, 1987, pp. 389-413.

[24] D. Bradley, M. Lawes, and M. Mansour, "Flame surface densities during spherical turbulent flame explosions," Proceedings of the Combustion Institute, vol. 32, pp. 1587-1593, 2009.

[25] N. Peters, Turbulent combustion: Cambridge university press, 2000.

[26] H. Kobayashi, T. Tamura, K. Maruta, T. Niioka, and F. A. Williams, "Burning velocity of turbulent premixed flames in a high-pressure environment," in Symposium (International) on Combustion, 1996, pp. 389-396.

[27] B. Renou and A. Boukhalfa, "An experimental study of freely propagating premixed flames at various Lewis numbers," Combustion science and technology, vol. 162, pp. 347-370, 2001.

[28] A. Thomas, "The development of wrinkled turbulent premixed flames," Combustion and flame, vol. 65, pp. 291-312, 1986. 